\title{
Confiança e negócios: uma relação delicada
}

\author{
Vera Lucia de Albuquerque Sant'Anna \\ Universidade do Estado do Rio de Janeiro
}

\begin{abstract}
This article analyses interviews involving Brazilian and Argentinian entrepreneurs working within the "Mercosul" economic community. The analyses aimed at identifying the means whereby these business partners construct their concepts of trust in relation to each other. By observing the strategies used in their spoken discourse, specifically those of parentheses and paraphrases, in addition to identifying the process of conflicting discourse organization, it was possible to detect various intepretations for the meaning of trust. In turn, contradictions were revealed between discourse organization which ought not to have been present in situation of confrontation in the first place. The world of "Mercosul" business exchanges, specifically those involving Brazilians and Argentinians, has thus emerged as a target of attacks which, in turn, ought to be the focus of concern of those responsible for political and economic decision-making.
\end{abstract}




\section{INTRODUÇÃO}

s relações comerciais, em especial as que se dão no contexto
das trocas internacionais, recebem grande atenção dos go-
vernos e dos empresários, pois são consideradas fundamentais para a manutenção do sistema econômico de um país e das próprias empresas. Hoje, momento de discussão das tendências de "globalização" de mercados, os brasileiros encontram-se participando de uma das maneiras de atualização desse processo, que são os chamados "mercados comuns". Trata-se do Mercosul, em cujo âmbito as trocas vêm se intensificando, transformando o panorama das exportações/importações dos países que o compõem (Brasil, Argentina, Uruguai e Paraguai). Considerando que entre o Brasil e a Argentina ocorrem os maiores movimentos comerciais, cabe questionar: o mundo dos negócios consegue fazer valer o objetivo maior da sua existência? qual o papel das interferências culturais e heranças históricas nesse contexto? como se constroem as relações de confiança entre os dois maiores parceiros desse mercado regional?

Para encontrar possiveis respostas a essas indagações, podemos seguir diferentes caminhos de pesquisa, com ênfase em fatores de ordem histórica, sociológica, antropológica, econômica... Porém, uma pergunta surge: de que modo uma pesquisa na área dos estudos da linguagem pode vir a contribuir para uma melhor compreensão do que se passa nesse contexto? Para nós, esse espaço de pesquisa insere-se num campo maior: o das práticas de linguagem no mundo do trabalho, incluindo-se nesse espaço diferentes formas de atualização. De modo geral, podemos dizer que se trata de uma proposta que busca descrever como se dão os processos de construção dos sentidos nesse mundo, a fim de auxiliar no entendimento de como as transformações sociais o afetam. 
Assim, como uma breve contribuição ao longo e complexo estudo que requer a análise dessas transformações históricoeconômico-sociais, propomo-nos a apresentar a observação de fenômenos constitutivos da organização da fala em situação de interação face a face, na busca de formas de estabelecer relações entre essa ocorrência - em especial o papel dos parênteses e da paráfrase - e sentidos estratégicos para o contexto significativo do diálogo. A base de dados utilizada é formada por entrevistas não-dirigidas, estimuladas pela leitura de um pequeno texto de jornal, gravadas em áudio, realizadas por pesquisadores junto a empresários brasileiros e argentinos que negociam no âmbito do Mercosul. O contato com estes empresários se deu na Federação da Indústrias do Rio de Janeiro (FIRJAN), onde ocorria uma "Rodada de negócios Mercosul".

Ainda que o foco central deste trabalho seja a análise da interação, considerando-se pressupostos da Análise da Conversação, interessa-nos, ainda, verificar possibilidades de articular a presença desses fenômenos de organização da fala a manifestações de sentido fundamentais para o objetivo da análise. Assim, como os fenômenos apreendidos nesse nível demonstraram ser insatisfatórios para expor as contradições que se manifestaram, fez-se necessário passar a outro nivel, em busca de pistas que fundamentassem tal contradição. Optamos por identificar formações discursivas - conforme apresentadas pela Análise do Discurso - em atrito: as relativas às trocas econômicas e as relativas à experiências vividas por cada um dos entrevistados.

Não se trata, contudo, de uma análise exaustiva do processo de contradição que se instaura, ao observar-se a palavra dos entrevistados. É muito mais um primeiro plano de análise, que aponta para possivel trabalho da ordem do interdiscurso. Faz-se necessário um estudo mais amplo, que remeta a outros discursos de diferentes ordens, proferidos em vários campos discursivos, no qual se possa observar o embate entre formações discursivas, na constituição de sentidos relevantes para a estruturação do mercado regional. O que aqui se propõe, porém, é uma breve observação de possiveis respostas às perguntas formuladas acima. 
Como pressuposto importante desta investigação, consideramos que tais processos de construção do texto falado, em situações nas quais os entrevistados se sintam constrangidos pelo tema e/ou pela presença do entrevistador, vão atuar como formas de "escapar", "atenuar" ou "disfarçar" manifestações que envolvam avaliações muito explícitas sobre o seu parceiro comercial. Considerando que os entrevistados ocupam o papel social de empresário, suas manifestações discursivas estão submetidas às questões éticas previstas nas relações econômicas. Fazemos a hipótese de que suas opiniões pessoais não devem (ou 'não deveriam) interferir no bom andamento dos negócios. Entretanto, as manifestações contra o diferente estão intimamente ligadas às relações de confiança e isso envolve questões decisivas, tais como segurança e risco, fundamentais para o mundo das trocas comerciais, em especial as internacionais. Sendo assim, no caso específico das relações de mercado entre o Brasil e a Argentina, no Mercosul, procuraremos observar como se explicitam as manifestações de confiança.

\section{ENTREVISTAS E ENTREVISTADOS}

A escolha da entrevista como forma de acesso aos empresários foi uma opção da pesquisadora, pois precisava penetrar num mundo de referência que não era o seu. Assim, conforme BLANCHET \& GOTMAN (1992), a entrevista é o instrumento que melhor propicia o acesso a um conhecimento em situações de experiências de vida desconhecidas do entrevistador. A modalidade não-dirigida, ainda que estimulada por um texto de jornal, foi a escolhida por haver um eixo temático de interesse para a pesquisa - o qual não foi informado aos entrevistados -, permitindo-lhes maior liberdade de expressão. Tínhamos consciência, contudo, de que a situação apresentava características da assimetria normal desse tipo de interação complementar, constrangedores dessa liberdade e, de certa forma, interferindo nas respostas - o entrevistador apresentava-se como pesquisador universitário, o que nos faz supor que o entrevistado preservaria mais 
a sua imagem tanto profissional como pessoal. Essa pressuposição tem por base o entendimento da entrevista, do ponto de vista pragmático-enunciativo, como uma situação na qual o papel dos protagonistas é, até certo ponto, fixo e pré-determinado. O entrevistador interroga, possui as perguntas, muda de tema, reinicia, portanto, ocupa uma posição "alta" na interação. Ao entrevistado cabe aceitar, comentar um determinado tema, sem questionar o entrevistador, situando-se em uma posição "baixa".

As entrevistas foram organizadas da seguinte forma: (1) seleção de uma breve notícia de jornal (anexo 1), com o objetivo de motivar a entrevista a partir de uma discussão sobre as relações comerciais entre Brasil e Argentina - nessa notícia, publicada no Jornal do Brasil de 25/04/95, comenta-se a entrada de um produto alimentício brasileiro, da fábrica Arisco, no mercado argentino, e as reações ao mesmo; (2) escolha do local onde se pudessem encontrar informantes com o perfil desejado; (3) definição de estratégia de aproximação aos empresários, constando de apresentação pessoal - "pesquisador universitário, da área de lingüística" - e do objetivo da entrevista - "conhecer a sua opinião sobre o tema da notícia do jornal"; (4) realização das entrevistas com alguns empresários que aceitaram ser entrevistados.

As gravações com os empresários argentinos ocorreram nas dependências da FIRJAN, enquanto as com os brasileiros se deram em seu local de trabalho, em dia e horário que lhes foram convenientes. Explica-se tal procedimento pelo fato de estarem os argentinos em visita ao Brasil, com agenda previamente definida para conversarem com negociantes brasileiros interessados em seu ramo específico, $O$ que obrigou o pesquisador a inserir-se em brechas de horário entre os encontros, naquele mesmo local.

Foram gravadas seis entrevistas, três com brasileiros e três com argentinos. Para este artigo, optamos por apresentar a análise de duas: (a) a de um brasileiro (transcrita no anexo 2) - empresário da área de transporte rodoviário; (b) a de um argentino (transcrita no anexo 3) - empresário da área de produtos alimentícios. Os procedimentos de transcrição seguiram os sugeridos por MARCUSCHI (1991). 


\section{ORIENTAÇÕES TEÓRICAS}

Os estudos sobre a conversação, com o objetivo de identificar fenômenos característicos do processo da fala, têm na Análise da Conversação (AC) uma sistematização bastante abrangente. Como toda teoria, conta com várias tendências e possibilidades de apresentação dos fenômenos em observação. Não nos propomos a um aprofundamento desse tipo de estudo neste trabalho. $\mathrm{Na}$ verdade, queremos desenvolver uma hipótese: a de que a identificação de certos fenômenos característicos da fala pode ser articulada a outros conhecimentos, com o objetivo de observar o papel que desempenham no sentido global da fala. No caso específico deste trabalho, estamos em busca de processos reveladores dos sentidos de confiança na fala dos entrevistados, quando estes se referem ao seu parceiro comercial.

Assim, optamos pela orientação do subgrupo "Organização textual-interativa”, que participa do Projeto Gramática do Português Falado, para a escolha dos conceitos relevantes para a análise, em relação aos fenômenos constitutivos de uma "gramática da conversação": os parênteses e as paráfrases. Trataremos, ainda que brevemente, de apresentar o sentido dos turnos de fala, sem, contudo, nos determos em detalhes das regras de gestão da alternância - uma vez que, em se tratando de uma entrevista não-dirigida, não é este o foco central. Utilizaremos alguns pressupostos da organização conversacional no nível global.

Os estudos do subgrupo "Organização textual-interativa" nos apontam para uma constatação fundamental: na análise do texto falado, importam as questões ligadas à desaceleração do ritmo da emissão do enunciado, porque elas sinalizam os recursos empregados pelo falante para formular e/ou reformular o dito - "Entre as principais estratégias de desaceleração do ritmo do texto falado, podem-se citar a inserção e a reformulação" (SILVA \& KOCH, 1996:329). Logo, se consideramos que o nosso contexto de entrevista encaminhava um tema delicado para o empresário, podemos acreditar que este precisaria utilizar mecanismos que o protegessem de uma exposição mais direta. 
Assim, para a seleção das categorias de análise do texto falado a serem observadas, considerou-se que o processo de reformulação e o processo de reforço-atenuação do conteúdo do tópico nos interessariam, em especial, porque:

- o entrevistado, ao reconhecer no entrevistador o pesquisador universitário, teria maior preocupação em expressar-se de forma clara e precisa, numa busca de garantir a compreensão do seu objetivo de comunicação, tendo em vista a natureza do tema em pauta, logo, recorreria a diferentes formas de reformulação de sua fala;

- o entrevistado desejaria demonstrar os seus conhecimentos específicos, não compartilhados com a entrevistadora, e, portanto, utilizaria "um discurso de autoridade" ou de "confiabilidade", que avalizasse o seu conhecimento sobre o tema, pois a expressão de questões polêmicas necessita de estruturas de apoio, remetendo à experiência vivida pela própria pessoa ou a valores de uma coletividade.

Dentre os processos de reformulação da fala e de reforçoatenuação do conteúdo do tópico a observar, decidimos nos deter:

a) na paráfrase - segundo Hilgert, "é um enunciado lingüístico que, na seqüência do texto, reformula um enunciado anterior, chamado de enunciado-origem ou matriz ( $M$ ), com o qual mantém, em grau maior ou menor, uma relação de equivalência semântica" (HILGERT, 1996:132), residindo sua importância no seu papel de reforço de argumentação;

b) nos parênteses - segundo Jubran, são marcas formais, "ocupando sempre uma posição intra-tópica, que promovem desvios momentâneos do quadro de relevância tópica de uma unidade textual. A definição de parênteses é, portanto, relacional: sua característica de elemento encaixado e desviante só se ressalta por contraposição a um dado contexto, recortado com base na dominância de um tópico discursivo" (JUBRAN, 1996:341); nosso interesse por identificar seu emprego está no papel de reforço/atenuação do conteúdo do tópico que pode adquirir relevância para a compreensão do processo de construção dos sentidos. 
Abrindo-se a outras pesquisas, a serem realizadas no futuro, o outro eixo teórico ao qual faremos referência é a Análise do Discurso, conforme vem sendo apresentada por MAINGUENEAU (1989, 1996, 1998). A dimensão dialógica da interação leva em consideração tudo o que torna o discurso heterogêneo, pois considera que a homogeneidade de um discurso só é possível enquanto efeito de sentido. $\mathrm{Na}$ concepção teórica de linguagem desenvolvida por BAKHTIN (1995), essa dimensão é apresentada como inerente a toda produção da linguagem humana - "o ato de fala, ou, mais exatamente, seu produto, a enunciação, não pode de forma alguma ser considerado como individual no sentido estrito do termo (...). A enunciação é de natureza social." (1995:109) - e se articula em dois eixos inseparáveis: a relação contextualizada, entendendo-se aqui um número complexo de fatores, entre os interlocutores de uma interação ("a situação social mais imediata") (1995:113) e, ao mesmo tempo, o diálogo que se estabelece entre outros discursos produzidos em diferentes espaços e tempos sóciohistóricos, que atravessam a produção de toda enunciação ("o meio social mais amplo") (1995:113).

Além da concepção dialógica da linguagem, recorremos a outras noções da AD de linha francesa, a saber: campo discursivo e formação discursiva. Para explicitar como estão sendo empregadas essas duas noções, é preciso considerar que há vários caminhos para explicá-las e aplicá-las numa análise do discurso. Não é nosso objetivo discutir exaustivamente essas questões de ordem teóricometodológica. Para este estudo, consideramos que num universo discursivo coexistem conjuntos de discursos que interagem em determinado momento. Para que o analista do discurso possa aproximar-se de seu objeto, uma vez que é impossível abarcar todos os conjuntos que formam tal universo, ele precisa recortá-lo em campos discursivos - trata-se, desde já, de uma crfação metodológica que variará segundo os objetivos da pesquisa e dos horizontes teóricos do pesquisador. O campo discursivo é, pois, um espaço construído pelo pesquisador, no qual um conjunto de formações discursivas estão em relação de concorrência, delimitando-se mutua- 
mente (MAINGUENEAU, 1996). A noção de formação discursiva está sendo compreendida como uma tendência que remete a "posicionamentos ideológicos marcados" (1996:42). Isto é, utiliza-se a noção de formação discursiva para delimitar discursos que estão em concorrência num campo discursivo, ou que podem estar apontando para concorrência entre campos discursivos distintos.

Tratamos, pois, o discurso como produção não exclusiva do indivíduo, mas como parte de uma construção que se opera a partir de perspectivas lingüísticas, discursivas, históricas e sociais. Outro elemento importante diz respeito às diferentes formas de estabeleceremse as concorrências entre formações discursivas, num determinado campo, e entre diferentes campos. Neste trabalho, observamos como cada um dos entrevistados posiciona-se diante do tema "confiança" na perspectiva das duas dimensões da dialogia. Consideramos, para efeito de análise, dois campos concorrentes: o do mundo das trocas econômicas e o mundo das falas cotidianas. Cada um desses campos se expressa a partir de várias formações discursivas, entre as quais selecionamos: a formação discursiva do mundo das trocas econômicas brasileiras e a formação discursiva do mundo das trocas econômicas argentinas;-a førmação discursiva das falas cotidianas brasileiras e a formação discursiva das falas cotidianas argentinas, respectivamente.

Retomando a questão da heterogeneidade discursiva, acreditamos que verificar na fala dos empresários algumas evidências da inclusão do "outro" pode revelar-nos algumas pistas para a compreensão dos sentidos atribuídos a "confiança". Sob o ponto de vista da $\mathrm{AD}$, as múltiplas formas da heterogeneidade enunciativa são o resultado da maneira pela qual o enunciador institui suas referências ao outro no interior do seu próprio discurso. Segundo MAINGUENEAU (1996, onde retoma a proposta de Authier-Revuz de 1982), podem ser considerados dois modos de atualização do fenômeno: a heterogeneidade mostrada (marcada ou não-marcada) e a constitutiva. Aqui, detemo-nos na heterogeneidade mostrada e marcada, aquela localizável "no fio do texto" a partir de marcadores pragmáticos explícitos. Não se trata, contudo, de um estudo sistemático dessas 
marcas. Utilizaremos sua identificação como recurso complementar às análises da constituição dos sentidos de "confiança", baseadas na identificação de campos e formações dicursivas.

Propomos, portanto, observar a constituição de sentidos para "confiança" a partir de movimentos que acreditamos serem complementares: a identificação de situações de reformulação e de reforçoatenuação do dito - analisados à luz da $\mathrm{AC}$ - como pistas da ordem do embate entre formações discursivas - analisada à luz da $\mathrm{AD}$ - quanto ao processo de contradição que se instaura para o sentido de "confiança".

\section{ESTRUTURAÇÃO FORMAL DOS DIÁLOGOS}

Tendo em vista os elementos de espaço e tempo disponíveis para cada uma das entrevistas, já explicitados anteriormente, vamos ter algumas diferenças de estruturação que foram levadas em consideração no processo de análise dos diálogos.

Observemos a distribuição dos turnos de fala e os sentidos que aí se constituem na entrevista com cada empresário.

\section{1 - O empresário brasileiro}

Há 18 turnos para o entrevistado (E1) e 19 para a pesquisadora (P); o número de linhas correspondentes às falas, entretanto, demonstra que E1 ocupa maior espaço discursivo, representado em número de linhas igual a 64, contra 24 de P. É natural que seja dessa forma, uma vez que o planejamento da entrevista não-dirigida, como modalidade de interação complementar, prevê essas regras.

Caracterização dos turnos de fala:

a) Turnos de P: caracterizam-se basicamente pelo emprego de reformulações - isto é, como esforço de quem deseja garantir a seu interlocutor a compreensão do seu objetivo de comunicação. Esta forma de retomar e manter o tópico de interesse da pesquisa 
atende à necessidade da entrevista não-dirigida. Nas linhas 53,55 , $65,84,90$ a tomada de turno se dá de modo brusco, com a intenção de fazer com que o entrevistado retorne ao tópico de interesse.

b) Turnos do E1: para efeito de análise, foram divididos em blocos, nos quais predomina uma determinada função - apresentação e construção de imagem positiva do parceiro, desconstrução dessa imagem, retorno à primeira imagem:

- bloco 1 - construindo uma imagem positiva do parceiro

linhas 5/20: apresenta-se; inicia o processo de construção da imagem positiva dos argentinos, apoiado na defesa das crenças dos mesmos. É um turno marcado pela presença de várias assertivas como forma de constatar uma verdade incontestável: "A comida argentina é melhor que as demais";

linhas 22/34: manutenção do processo anteriormente iniciado;

- bloco 2 - desconstruindo essa imagem

linhas 44/52: inicia-se o seu processo de atenuação do ponto de vista categórico, anteriormente construído;

linhas $56 / 61 ; 80 / 83 ; 85 / 89$, após a mudança do rumo de sua fala, deixa transparecer juízo de valor em relação a seus parceiros, chegando mesmo a afirmar que o argentino não ganhou credibilidade aqui, apoiado por recursos extralingüísticos - risos - que corroboram a expressão do juízo emitido;

linhas 91-95: volta a empregar recurso extralingüístico para ressaltar a existência de uma relação difícil, de longa data (estalar dedos), sem, contudo, verbalizá-la;

- bloco 3 - retorno à imagem positiva

linhas 97/100: quer desfazer qualquer idéia de juízo de valor negativo que possa ter expresso, recorre a enunciados que expressam a necessidade de confiar em seus parceiros, de tal forma reiterada, que funciona como processo de convencimento do seu interlocutor e de si mesmo. 


\section{2 - O empresário argentino}

A entrevista conta com a mesma organização da do brasileiro. Há uma equivalência entre o número de turnos do entrevistado (E2) e da pesquisadora $(\mathrm{P})$, totalizando 16 cada um. O número de linhas correspondente às falas, entretanto, demonstra que E2 ocupa maior espaço discursivo: 30 contra 17 de P.

\section{Caracterização dos turnos de fala:}

a) Turnos de P: como na entrevista com E1, mantém-se o traço marcante do emprego de reformulações;

b) Turnos do E2: observa-se a existência de um grande bloco significativo, pois não apresenta mudanças no seu ponto de vista sobre seu parceiro:

linhas 2/14 e 20/31: apresenta-se; organiza a explicação de seu entendimento sobre o texto e entra no tópico de interesse da pesquisa;

linhas 33/41: estabelece uma busca pela precisão de conceitos em relação à negociação e a como esta se dá com o Brasil. Na fala das linhas $43 / 44$, expressa de forma direta, sem qualquer estímulo de $\mathrm{P}$, o seu ponto de vista sobre seu parceiro. Essa forma direta de E2 surpreendeu P, envolvendo-a na manifestação extralingüística do riso e encerrando a entrevista logo a seguir.

\section{IDENTIFICAÇÃO DE OCORRÊNCIAS DE PARÊNTESES E PARÁFRASE}

Observamos uma sensível diferença no emprego dessas duas estratégias de organização da fala em cada uma das entrevistas dos empresários. Em relação ao empresário brasileiro sobressai o emprego de parênteses, enquanto que na fala do empresário argentino sobressai o da paráfrase. Assim, optamos por proceder à análise da estratégia mais empregada por cada entrevistado, pois, a partir de sua incidência, podemos fazer a hipótese de que o tema 
básico da confiança, não explicitado claramente pela entrevistadora, vai ser alvo de especificação/expansão de sentido, de maneiras diferentes em cada entrevista.

\section{1 - O reforço-atenuação: o uso dos parênteses ${ }^{2}$}

Em geral, o aparecimento de parênteses está associado a uma digressão do falante, quer para melhor esclarecer o tema básico, quer para remeter a um subtema, quer para afastar-se dele, em momentos de dificuldade. É um processo que tem uma função metaconversacional, uma vez que costuma vir introduzido por marcadores discursivos que fazem com que o interlocutor perceba a digressão, mesmo que não consiga, num primeiro momento, apreender o seu sentido.

Observemos as seguintes ocorrências (na fala do empresário brasileiro):

1. linhas 11/13: (+) falando sobre a Arisco (+) o que eu posso comentar não é bem a ÁREA que eu atuo $(+)$ a minha área é mais o transporte uma prestação de serviço $(+)$ é é verdade $(+)$ os produtos brasileiros até então não eram muito aceitos na Argentina (+)

2. linhas 14/15: e menos os comestíveis (+) porque o argentino / eu que morei lá um tempo / até por questões de trabalho $(+)$ né" os produtos são de primeira qualidade (+)

3. linha 88/89: o brasileiro ainda NÃO conseguiu ainda se entrosar cem por cento lá com a Argentina / eu [ morei lá]

4. linhas 38/39: não vejo NUNCA tivemos NEnhuma / pelo menos nós prestadores de servico / inclusive eu tô:: há vinte anos trabalhando nessa área ( + ) e:: / houve assim ( + ) um ou outro desentendimento $(+)$ mas::s coisas normais $(+)$

5. linhas 66/70: NÃO não não não (+) os problemas normais (+) por exemplo nós $(+)$ como prestadores de serviço $(+)$ nós ((incompreensivel)) temos dificuldade / agora o o intercâmbio deu uma caída 
(t) de 3 meses pra cá (t) abaixou:: 40 a 50\% (t) a a nossa movimentação entre a Argentina e o Brasil $(t)$ mas ANTES $(t)$ há 3 meses antes $(t)$ de outubro até::: fevereiro marco $(t)$ mais ou menos $(+)$ e::ra IMPRESSIONANTE o movimento /

Os afastamentos do conteúdo do tópico nos fragmentos têm sentidos diferentes:

(a) no fragmento 1, o entrevistado se desqualifica profissionalmente ele não é da área abordada pelo texto motivador - para atenuar o que vai dizer logo a seguir, parte central da sua opinião. Assim, o interlocutor se prepara para conhecer a visão de um nãoespecialista; logo, pode desconsiderá-la ou, pelo menos, não levá-la muito a sério;

(b) os fragmentos 2 e 3, entretanto, vêm no sentido oposto: como morou na Argentina é pessoa qualificada para emitir opiniões que envolvam julgamentos avaliativos. Suas observações sobre os produtos argentinos devem ser consideradas importantes, pois são a expressão do seu ponto de vista, pautada na sua experiência pessoal, portanto, indiscutivel;

(c) os fragmentos 4 e 5 também reforçam o que está apresentado no tópico, mas a partir de um discurso de autoridade profissional ele é parte de um grupo profissional que não costuma ter problemas nos negócios com seus parceiros argentinos, tema do tópico - aqui, o marcador metadiscursivo "por exemplo" introduz um problema considerado "normal".

Nos fragmentos a seguir, os parênteses, ao se afastarem do tópico, voltam-se muito diretamente para a entrevistadora, porém com sentidos diferentes:

6. linhas 71/72: /inclusive até esse nosso cliente $(+)$ que foi apresentado através de vocês/tivemos dificuldade pra poder tirar a mercadoria

7. linhas 97/100: eu acredito que:: (+) ACREDITAR: (+) e:: (+) TER:: CONFIANÇA $(+)$ PRIMEIRO logicamente antes de você comprar 
uma mercadoria qualquer coisa $(t)$ você tem que saber $(t)$ quem vai fabricar" $(+)$ quem vai te vender " $(+)$ a partir da;i $(+)$ ter confiança $(+)$ e esperar:: o resultado $(+)$ de outra maneira $(+)$ eu não vejo $(+)$ é ter confiança

O fragmento 6 cria uma relação de proximidade com a entrevistadora, desfazendo uma distância previsível entre as partes da interação: entrevistador e entrevistado conhecem uma mesma pessoa, o que os torna mais próximos. O afastamento do tópico é total, mas cria uma aproximação com a situação vivida.

Já no fragmento 7, podemos dizer que o discurso do entrevistado adquire traços de didaticidade, quando se propõe a dar explicação do sentido da palavra confiança a um "você" de caráter genérico, no qual está incluída a interlocutora. São explicações que parecem óbvias, mas que adquirem caráter informador fundamental, pois fazem parte do processo de romper a assimetria "superior" do entrevistador: quem detém o conhecimento sobre o mundo dos negócios é o entrevistado. Logo, a retomada do tópico adquire um caráter ainda mais revelador: ter confiança em alguém no mundo dos negócios é coisa diferente de seu sentido em outros mundos, é preciso conhecer as relações comerciais para saber confiar.

Uma ocorrência de parênteses adquire especial relevância, no fragmento 8 , pois, na busca de melhor explicar a negativa contida no tópico, o entrevistado exemplifica sua idéia com uma situação narrada em forma de lembrança pessoal, que, em lugar de apoiar seu tópico, afasta-se a ponto de negá-lo:

8. linhas 44/52: não (++) é pode ser (+) alguma questão assim (+) de de qualidade $(+)$ em algum produto $(+)$ mas assim uma coisa bem FORA $(+)$ da da digamos / que pode acontecer $(+)$ da mercadoria que foi embarcada $(+)$ e deu algum problema / eu lembro de produtos $(+)$ que / às vezes eles compram determinado produto / isso acontece ao contrário $(+)$ da Argentina pra aqui ( + ) isso acontecia muito $(+)$ por exemplo $(+)$ o:: brasileiro vai lá na Argentina $(+)$ pra comprar couro $(+)$ lá a qualidade do couro 
realmente é boa $(+)$ então de repente $(t)$ que que acontece" $(+)$ ele comprou um couro de uma qualidade $(t)$ e depois quando foi embarcar $(+)$ a mercadoria $(+)$ a qualidade era outra $(++)$ então isso nessa época acontecia muito $(+)$ hoje eu sei que isso já acabou

Ao recorrer a uma narrativa de caráter histórico, retornando a um passado não muito distante no tempo, constrói sua justificativa para exemplificar uma situação apresentada como diferente da que se tem hoje. O marcador metadiscursivo "por exemplo", nesse trecho, introduz problema considerado "grave" e é a chave para a apresentação dos parceiros comerciais sob ponto de vista negativo, com uma afirmação final que procura amenizar o exemplo ("nessa época acontecia muito, hoje eu sei que isso já acabou"). Porém, o tema da confiança se faz presente, não de forma direta, mas pela situação de logro - comprar uma coisa e levar outra -, acontecimento extremamente grave para a confiança no mundo dos negócios.

\section{2 - A reformulação: o uso da paráfrase ${ }^{3}$}

Os processos de reformulação podem ser entendidos como expansões discursivas e, como tal, asseguram a organização geral da fala, mostrando como um falante mantém uma continuidade formal. A paráfrase, portanto, como parte deste processo, constrói equivalências motivadas por uma situação de interação específica.

O empresário argentino encontrava-se diante de um interlocutor que não compartilhava dos mesmos conhecimentos sobre a língua, sobre cultura, ainda que $P$ tivesse mantido a conversação em língua espanhola. Como conseqüência, a sua fala vai estar marcada pela busca de maior precisão e clareza.

Observemos as ocorrências (na fala do empresário argentino):

1. linhas 17 - 24

P. sí aquí hay algunos problemas (+) que envuelven negocios $(+)$ negociaciones $\mathrm{E}$ [Sí

P. cuál de ellos le llamó más la atención" que le gustaría comentar::

E. no:: $(+)$ me $(+)(+)$ llamó la atención $(+)$ esto que $(+)$ e:: $(+)(+)$ un argentino $/$ un brasileiro en la publicidad $(+)$ le da más importancia a la parte senSIble 
$(+)(++)$ y que un argentino le da más importancia al proDUCTO (+)

P.

[hum hum]

E. / e:: (+) me llamó la atención (+) esa característica

Observemos o processo de substituição que E2 faz para a palavra "problema" introduzida por P: "esto que" e "característica". $\mathrm{Na}$ verdade, ele centrou-se no detalhe de como tinham sido feitas as campanhas publicitárias nos dois países para um mesmo produto, evitando qualquer referência a "problemas". Chama a atenção, pois o entrevistado brasileiro não se deteve nesse trecho da notícia. Sabemos que a publicidade conhece os mecanismos para aproximarse de determinado público consumidor e esta explicitação fez com que o argentino começasse suas observações por essa preferência, enfatizadas pela entonação. Neste trabalho, não nos deteremos no estudo da entonação, que requer todo um conjunto de ferramentas específicas para a sua análise.

Parece-nos que representa uma reflexão de cunho cultural relevante para o desenrolar do diálogo a atenção dada pelo entrevistado argentino ao fato de que ao brasileiro interessa mais a parte sensível - atributo subjetivo - e ao argentino, o produto - atributo objetivo.

Logo a seguir, a pesquisadora força o retorno à palavra "problema", isto é, ao tema de interesse da pesquisa, através do emprego de uma paráfrase, expandindo o sentido dessa palavra, com o objetivo de fazer o entrevistado penetrar no campo semântico do seu interesse:

2. linhas $25-6$

P. sí $(+)$ además de esto $(+)$ este problema inicial $(+)$ respecto a la cuestión de calidad $(+)$ de creer en un producto o de no creer:

O entrevistado, porém, continua evitando a referência à palavra "problema", recuperando o enunciado matriz com nova paráfrase "proceso lógico":

3. linhas $27-31$

E. bueno, $(+)$ eso es un:: proceso lógico $(+)$ quiero decir $(++)$ que ha sido $(++)$ e:: $(+)$ / hay artículos en los cuales ( + ) Brasil está asociado a buena calidad (++) uno nombra algodón en Argentina $(+)$ brasileiro / una prenda de algodón y 
el argentino no se va a dudar que es de mejor calidad que en Argentina (++) uno nombra:: $(++)$ otro artículo de Brasil $(+)$ y sí se puede dudar que la calidad es inferior a la que estamos acostumbrados en Argentina (+) depende del artículo

Sente necessidade, porém, de especificá-la através da apresentação de um exemplo concreto, ligado à sua experiência e à de todos os argentinos, sobre o tema de crer ou não em um produto, introduzida pelo marcador "quiero decir". Este exemplo trabalha com os verbos "dudar" e seu oposto direto "no dudar".

Outra paráfrase importante é a empregada pelo entrevistado no processo de especificação do que venha a ser o papel da qualidade de um produto nas relações comerciais. A explicação é detalhada. Seu objetivo, portanto, é dar a seu interlocutor uma informação bem próxima do que seja a relação comercial, no que diz respeito aos problemas, por um lado, da confiança, e, por outro, do medo/ risco, mas sem mencionar as palavras "problema" e "confiança":

\section{4. linhas 33-41}

E. en el negocio / si se está trabajando un artículo $(+)$ el cual $(+)$ uno tiene en su inconsciente una mala calidad $(+)$ tiene que hacer $(+)$ trabajar más para demostrar que es una buena calidad (++) si esa persona ya sabe que va a comprar algo que de por sí es de mejor calidad ( + ) es más fácil / menos riesgo $\angle$ menos miedo

P [ hum (+) hum

E / siempre es esto si tenemos menos miedo es más fácil ( + ) si tenemos miedo todo es más difícil $(+) /$ miedo comercial eh:

$P \quad$ claro $(+)$ claro

E /miedo para evitar riesgo $(+)$ de calidad de entrega y de servicio

Uma observação especial pode ser feita em relação ao processo de especificação da palavra "medo", que articula conceitos inversamente proporcionais:

MAIS CONFIANÇA $=$ MENOS RISCO, MENOS MEDO

MENOS CONFIANÇA $=$ MAIS RISCO, MAIS MEDO

Logo, o medo de correr o risco de obter qualidade, entrega e/ ou serviço não-esperados é balizado pela maior ou menor confiança 
no parceiro, no que coincide com o temor do brasileiro, apresentado em forma de narrativa historicamente contextualizada.

Pode-se perceber a partir dessa especificação que o entrevistado deixa clara a sua visão de como se processam as relações interpessoais no mundo dos negócios: estrutura-se na antinomia entre confiar / desconfiar.

Esta primeira parte da análise da interação, a partir do estudo do papel estratégico do emprego de parênteses e paráfrases na fala dos empresários, deixou uma pergunta no ar: afinal, o que é "confiança"? Se confiar é desconfiar, se confiar é ter medo, é estar correndo riscos, percebemos uma contradição expressa através dessa inversão de sentidos. Mas, de onde vem tal contradição? Que pistas podemos seguir para tentar resolver como ela se instaura? Uma hipótese possivel da origem dessa contradição estaria no cruzamento de discursos oriundos de dois campos discursivos distintos, cujo embate provoca esta forma especial de criação de sentidos atribuídos à "confiança". É esse rumo de análise que apresentamos a seguir.

\section{TEMA DA "CONFIANÇA" E FORMAÇÕES DISCURSIVAS EM EMBATE}

Nas interações analisadas ressalta-se o seguinte fato: os dois entrevistados são empresários, ou seja, estão circunscritos em um campo discursivo que define o mundo das trocas econômicas. Incluem-se neste campo as formações discursivas concorrentes que definem a dimensão sócio-histórica de cada um: a formação discursiva do mundo dos negócios brasileiros e a formação discursiva do mundo dos negócios argentinos. Assim, têm relações análogas com seus parceiros comerciais, porém não partilham o mesmo conjunto histórico-lingüístico-cultural. No entanto, participam concomitantemente de outro campo discursivo: o das falas cotidianas, baseadas na experiência vivida por cada um dos grupos sociais em que estão incluídos, extra-mundo dos negócios.

O campo discursivo das trocas econômicas, ou o das falas cotidianas, na verdade, não inclui diretamente a entrevista realizada 
pela pesquisadora. A situação de interação é entre uma pessoa nãoidentificada como parceira e um empresário, que sabe exatamente quem é o seu parceiro comercial. Podemos observar que cada um dos empresários deixa perceptível na sua enunciação a sua inclusão nos dois campos discursivos, que se atualizam em uma infinidade de formas não-incluídas neste estudo, mas que dariam uma visão mais profunda do fenômeno, por exemplo:

1. discursos do mundo das trocas econômicas - atualizados em discursos oficiais sobre o Mercosul (legislação, regras de funcionamento nas suas diversas instâncias de decisão); publicações/livros que analisam diferentes componentes do andamento do seu processo de formação/andamento; textos da imprensa ou de outras fontes que de alguma maneira remetem ao mercado regional;

2. discursos do mundo das falas cotidianas - que retomam a experiência vivida por cada um dos empresários, relativas ao mundo dos negócios ou não (por exemplo, o brasileiro faz referência a problemas no âmbito do futebol e "uma série de coisas", não-especificadas).

Reconhecer as limitações deste estudo obriga-nos a buscar caminhos para explicar a contradição identificada na análise da interação. É o que apresentamos a seguir, a partir da observação da constituição dos sentidos de "confiança" em cada uma das formações discursivas explicitadas anteriormente.

Para observar alguns elementos de constituição dessas formações discursivas, optamos por analisar dois momentos, em especial, que se revelam exemplares para a constituição dos sentidos de confiança, quando:

1. ocorre uma explicitação no nível lexical do tema da confiança, como parte do mundo das trocas econômicas;

2. apresenta-se a confiança no parceiro, como indivíduo.

O primeiro momento, relativo à formação discursiva do mundo das trocas econômicas, diz respeito a duas formas de expor e reformular o tema da "confiança", no nível lexical: 
- para o argentino, cabe explicar o que vem a ser "medo comercial" - medo para evitar risco, de qualidade, entrega e serviço, comerciar com menos risco tem como conseqüência menos medo, logo é mais fácil a transação. Em nenhum momento a palavra confiança é citada, porém ela está implicada em toda a explicação: ter menos medo é ter confiança no outro, mas é preciso ter medo, não ter confiança, para evitar riscos - definese um sentido específico de confiança;

- para o brasileiro, aparece a palavra confiança, mas esta adquire sentidos constituídos nesse mundo de negócios, a palavra vem acompanhada de uma explicação que especifica o sentido atribuído pelo empresário: antes de você comprar uma mercadoria é preciso saber quem fabrica, quem vende e, então e só então, nasce a confiança. Ela, na verdade, também se constitui a partir da desconfiança.

Podemos dizer que esse seria o modo de operar do campo discursivo que contém o mundo das trocas econômicas, havendo uma coincidência total entre as duas formações discursivas: todos têm confiança, porém é uma em especial, que nasce da desconfiança, do medo do risco. Logo, brasileiro e argentino concordam com o sentido atribuído a confiança no mundo dos negócios, tomado como espaço coincidente do movimento de cada um deles. Há, portanto, entre formações discursivas concorrentes, um sentido de aliança, onde se enfatiza a confiança, pois, como empresários participantes da constituição do mercado regional, partilham tal sentido .

O segundo momento identificado, o da apresentação da confiança no parceiro, expõe o discurso das falas cotidianas atravessando o campo das trocas econômicas. Quando cada um dos empresários remete a seu parceiro - o "outro", identificamos marcas de heterogeneidade mostrada, marcada, que auxiliam na compreensão do processo de contradição que se instaura:

- para o argentino não há preâmbulos, quando a entrevistadora quer saber se está funcionando bem esse processo de ter medo para evitar risco, sem que tivesse feito nenhum direcionamento específico para que ele falasse de um parceiro brasileiro, pois ele 
poderia ter optado por falar em geral. O empresário usa a estratégia de recuperar a palavra do outro, imitando-o na pronúncia e na entonação, fazendo-o na língua desse outro - o português: "Yo diría que con Brasil el FICA TRANQUILO todavía nos preocupa", para desqualificar a estrutura imitada e, ao fazêlo, valoriza a sua opinião negativa sobre o parceiro brasileiro. $\mathrm{O}$ emprego do pronome nós ("nos preocupa") recupera a força da categoria de empresários argentinos, na qual se insere. Não se trata de opinião pessoal, mas da manifestação de um determinado grupo social, a cujas regras encontra-se presa a relação comercial. Vale lembrar que a imitação do "outro" é uma das manifestações mais visíveis da heterogeneidade, porém seus possíveis sentidos estratégicos se polarizam entre subverter - para derrubar/ desvalorizar o outro - e reafirmar o imitado - para revalorizar a si mesmo a partir do outro (MAINGUENEAU, 1989);

- para o brasileiro, o processo é um pouco diferente. Ele é diretamente interpelado pela entrevistadora a manifestar-se sobre a relação com o parceiro ("quer dizer, se um argentino disser para você assim 'pode deixar, deixa comigo', você acredita?"), e este, quando o faz, hesita, mas deixa clara a sua posição de dúvida: "vou tentar acreditar". Esta frase, acompanhada de uma explicação um tanto hesitante e de elementos não-verbais (risos), acaba por reforçar a sua dúvida primeira. Podemos acompanhar a constituição do sentido de desconfiança no parceiro argentino quando o brasileiro retoma sua fala em primeira pessoa, para explicar, detalhar, justificar o que foi dito por ele mesmo, remetendo-nos à imagem que constrói de si mesmo e do outro, o parceiro argentino:

“... é verdade, os produtos brasileiros até então não eram muito aceitos pela Argentina e menos os comestiveis ... eu morei lá um tempo até por questões de trabalbo, os produtos são de primeira qualidade...";

"... os argentinos acham que a sua comida, a sua alimentação é a melbor e realmente é de primeira qualidade..."; 
"eu lembro de produtos ... por exemplo, o brasileiro vai lá na Argentina comprar couro....então de repente ... ele comprou um couro de uma qualidade e depois quando foi embarcar a mercadoria a qualidade era outra ... boje eu sei que isso já acabou, quer dizer eles vend....";

"eu vou tentar acreditar, mas não, mas realmente não, veja bem tem gente, como também pode haver a dúvida com o brasileiro, mas o argentino ainda não ganhou a credibilidade cem por cento, ainda existe uma certa ...";

"o brasileiro é bem mais respeitado na negociação para o argentino, que o argentino é aceitado pelo brasileiro, eu acredito que não é nem só pela talvez pela falta de seriedade, que não existe isso, mas é que o brasileiro ainda não conseguiu ainda se entrosar cem por cento lá com a Argentina, eu morei lá".

A marca de heterogeneidade que comentamos, ainda que brevemente, é a de algumas formas da denominada "negação polêmica" - na qual se rejeita um enunciador mobilizado no discurso, enunciador este que não é o locutor de um enunciado realizado, pois o que é rejeitado é construído no interior da própria enunciação que o contesta (MAINGUENEAU, 1989:84). Estas marcas explícitas de uma heterogeneidade que delimita um outro, que está fora do discurso e que afirma o contrário do dito, faz-nos refletir sobre quem seriam esses outros, responsáveis por enunciados como:

a) "eu vou tentar acreditar, mas não, mas realmente não, veja bem tem gente, como também pode haver a dúvida com o brasileiro, mas o argentino ainda não ganbou a credibilidade cem por cento, ainda existe uma certa ..."

- o enunciador ao deixar transparecer a sua dúvida na confiança no parceiro argentino, repete uma estrutura negativa, passando a seguir a um esforço de amenizá-la ("veja bem tem gente, como também pode haver a dúvida com o brasileiro"), pois pode haver dúvida também em relação aos procedimentos dos brasileiros. A frase seguinte, contudo, volta à negação - se ele mesmo era o 
enunciador de que tudo estava caminhando bem, agora ele nega a ele mesmo enquanto enunciador da carga positiva com a qual se tinha identificado anteriormente ("mas aquele problema mesmo sério, já se acabou hoje"), e expõe que o argentino "ainda não ganhou credibilidade cem por cento";

b) "o brasileiro é bem mais respeitado na negociação para o argentino, que o argentino é aceitado pelo brasileiro, eu acredito que não é nem só pela talvez pela falta de seriedade, que nâo existe isso, mas é que o brasileiro ainda não conseguiu ainda se entrosar cem por cento lá com a Argentina, eu morei lá".

- aqui o enunciador utiliza uma carga redobrada de negação - não é nem só pela talvez ... - o que faz com que pensemos num enunciador externo que afirma uma "falta de seriedade" por parte dos argentinos, acompanhada de outras questões problemáticas. Afinal, não é nem só talvez pela falta de seriedade que podem estar ocorrendo problemas de confiança: há outras variáveis não explicitadas, porém incluídas no "nem só". Segue-se um esforço do locutor de negar o que ele mesmo acaba de afirmar: "que não existe isso" de falta de seriedade. O que existe então? Ele explica: o brasileiro é que ainda não se entrosou cem por cento lá na Argentina. Atenua-se a crítica anterior, baseada na experiência vivida "eu morei lá" - como, por exemplo, quando do relato da troca de mercadorias citada em outro fragmento, que remete à desconfiança.

E o que será que significa estar ou não estar entrosado em/com outro país? Que relação tem com os negócios o entrosamento entre pessoas de países diferentes? Não temos condições de encaminhar respostas a estas perguntas neste trabalho, porém ficam lançadas para que em outro momento possamos perseguir essas pistas e penetrar um pouco mais nesse mundo, ainda pouco conhecido, das relações comerciais-individuais que se estão construindo entre brasileiros e argentinos.

Podemos, contudo, afirmar que cada entrevistado, a seu modo, marca uma oposição com o "outro" no campo das falas cotidianas, que não se tinha verificado na caracterização do campo discursivo 
do mundo dos negócios. Não se pode afirmar, entretanto, que meras questões individuais estavam sendo expostas na oposição entre os indivíduos-parceiros. Estamos na esfera de formações discursivas das falas cotidianas, nas quais elementos sócio-históricos diferenciados entram em ação e interferem nas outras formações que dizem respeito ao mundo das trocas comerciais, que, em princípio, se mostraram complementares.

A formação discursiva das vivências argentinas e brasileiras ${ }^{4}$ entra em concorrência com a formação discursiva do mundo das trocas econômicas: é nesse cruzamento de discursos oriundos de campos discursivos distintos que nasce a contradição de sentidos identificados para "confiança". A confiança desconfiada do mundo dos negócios nada mais é do que uma desconfiança entre partes que não podem enfatizá-la enquanto indivíduos, sob pena de estarem impedidos de dar continuidade às negociações do mundo empírico, que envolvem a sobrevivência e os lucros, facilitados pela existência do mercado regional. Um campo discursivo atravessando outro e fazendo com que formações que não estariam em choque passem a se chocar nos fazem pensar sobre os rumos a que se propõe o Mercosul. Mas para uma análise mais profunda do processo, é preciso ampliar o corpus de estudo, incluindo-se outras fontes de informação sobre a organização do mercado regional, bem como outras noções de base discursiva, capazes de oferecer uma visão das diferentes constituições de sentidos nesses discursos.

\section{CONCLUSÕES}

Do ponto de vista metodológico, queremos retornar a dois aspectos:

1. a pertinência de análises discursivas que remetem ao mundo do trabalho, aqui representado pelas trocas comerciais;

2. a possibilidade de inter-relações entre propostas teóricas - a AC e a $\mathrm{AD}$-, como uma possibilidade de alcançar um nível mais profundo de compreensão do processo de produção de sentido numa enunciação em interação face a face. 
As análises discursivas que remetem ao mundo do trabalho têm como um de seus objetivos mais importantes propiciar a "emergência de saberes não-expressos" (FAÏTA, 1995:84). Isto significa que as ações de verbalização sobre o trabalho, emitidas por aqueles que o realizam, não são, normalmente, tratadas como informações relevantes pelos que detêm os meios e os poderes. São saberes nãoexpressos que precisam encontrar canais para serem reconhecidos. O papel do lingüista é, portanto, trazer esse conhecimento para um espaço de discussão mais amplo, se possível com a companhia de profissionais de outras áreas.

Desse modo, aproximar-nos do mundo das trocas comerciais, por meio da fala de dois pequenos empresários, fez-nos conhecer um conceito de confiança duplamente constituído: se, por um lado, ele é partilhado - desconfia-se para negociar -, por outro, ele constrói caminhos que não se cruzam - reciprocamente, não há confiança entre pessoas. Instaura-se uma contradição que o mundo das trocas comerciais não pode suportar: pessoas não podem ser mais importantes que os negócios.

Essas conclusões só foram surgindo à medida que avançavam as análises, tanto de fenômenos da conversação, como de questões discursivas. Tratamos, então, da tentativa de equilibrar duas vertentes de análise e foi possível observar que não existe contradição em fazêlo: se a complementaridade pode ser discutida, pois são duas linhas que seguem seus próprios caminhos, não o será a possibilidade de sua articulação. Ambas defendem uma concepção de linguagem dialógica, que, mesmo que busquem na materialidade lingüística traços um tanto diferentes, se tocam no que poderíamos chamar um horizonte teórico mais amplo: o dos discursos teóricos sobre a linguagem que rechaçam concepções que não integram enunciador/ enunciação/co-enunciador e situação sócio-histórica (mesmo que as nomenclaturas revelem algumas diferenças teóricas).

A AC ofereceu os mecanismos de verificação de construção de fala - parênteses e paráfrases - que remeteram a contradições, o que nos encaminhou à $\mathrm{AD}$, em busca de compreender a relação dialógica 
entre os entrevistados e seus "outros" - marcados pela característica da heterogeneidade enunciativa -, a partir das noções de campo e formação discursiva.

Do ponto de vista das informações obtidas com a análise, podemos ressaltar:

1. o papel do não-verbal como fundamental para fixar determinadas possibilidades de compreensão, como, por exemplo, os risos;

2. a implicação entre blocos de turnos e sentidos globais da interação numa entrevista;

3. o papel revelador de sentidos que adquirem certas estratégias das interações face a face;

4. um tema pré-determinado, mas sem garantias de sua ocorrência, como revelador dos mecanismos de avaliação sobre o outro;

5. as instâncias do campo discursivo e da formação discursiva como uma necessidade surgida do próprio percurso da análise, uma vez que o primeiro nível mostrou-se insuficiente para explicitar a natureza do processo de contradição observado na constituição dos sentidos de "confiança".

Como últimas palavras, gostaria de retomar a questão do choque entre formações discursivas que não deveriam estar em oposição, mas que estão e acabam por chocar-se - no campo das falas cotidianas onde cada um manifesta desconfiança no parceiro, contrariando a complementaridade constatada no sentido atribuído à confiança no campo das trocas econômicas. A criação de mercados regionais, como o Mercosul, cuja função básica é a de criar condições de maior confiança e menor risco para as transações comerciais entre semelhantes, sofre um ataque com a análise que constatamos. Naturalmente, isso não quer dizer uma impossibilidade de continuidade ou execução no mundo empírico, mas revela problemas nãoapontados pelos que gerenciam o processo, ou porque os ignoram, ou porque não lhes convém. Resta a dúvida. Afinal, estamos mesmo no campo da desconfiança, ou não? 


\section{NOTAS}

' Não entraremos em considerações teóricas sobre as diferentes concepções do que venha a ser globalização/mundialização. Contudo, deixamos claro que é discussão aberta e que merece um estudo discursivo a partir de diferentes fontes de informação.

${ }^{2} \mathrm{O}$ trecho considerado como parte integrante dos parênteses encontra-se sublinhado.

${ }^{3} \mathrm{O}$ trecho considerado como parte integrante da paráfrase encontra-se sublinhado.

${ }^{4}$ Os elementos históricos e sociais, que agem na formação discursiva das vivências desses dois povos, dizem respeito às relações de "permanente rivalidade" desde as metrópoles ibéricas, a República (Argentina) e a Monarquia (Brasil), o período da Segunda Guerra Mundial, com seu ponto culminante nos anos 70. Para SEITENFUS (1995:42), "será baseada na fraqueza de um incipiente poder civil e na impossibilidade material de dar continuidade à excêntrica rivalidade, que Brasília e Buenos Aires decidem recorrer ao diálogo". A base do programa de cooperação entre os dois países nasce, assim, sob a égide do esforço oficial por um processo de aproximação de caráter primordialmente econômico.

\section{REFERÊNCIAS BIBLIOGRÁFICAS}

BAKTHIN, M. Marxismo e filosofia da linguagem. 7.ed. São Paulo: Hucitec,1995. BLANCHET, A., GOTMAN, A. L'enquête et ses méthodes: l'entretien. Paris: Nathan, 1992.

FAIITA, D. Dialogue entre expert et opérateur: contribution à la connaissance de l'activité par l'analyse des pratiques langagières. In: CONNEXIONS: Dire et faire le travail. Paris, Érès, n.65, p.77-98, 1995.

HILGERT, J. G. As paráfrases na construção do texto falado: o caso das paráfrases em relação paradigmática com suas matrizes. In: KOCH, I. G. (Org.). Gramática do português falado. v. VI. Campinas: Ed. Unicamp/FAPESP, 1996. p.131-147.

JORNAL DO BRASIL. Rio de Janeiro, 25 abr. 1995, Caderno Negócios e Finaças, p.15.

JUBRAN, C. C. A. S. Parênteses: propriedades identificadoras. In: CASTILHO, A. T., BASÍlIO, M. (Org.). Gramática do Português Falado. v. IV. Campinas: Ed. Unicamp/FAPESP, 1996. p.411-421. 
MAINGUENEAU, D. Analyser les textes de communication. Paris: Dunod, 1998. . Les termes clés de l'analyse du discours. Paris: Seuil,1996. . Novas tendências em análise do discurso. Campinas: Ed. Unicamp-Pontes, 1989.

MARCUSCHI, L. A. Análise da conversação. 2.ed. São Paulo: Ática, 1991.

SEITENFUS, R.A.S. Um Mercosul para poucos: considerações sobre o desperdício de uma grande idéia. São Paulo em Perspectiva, São Paulo, Revista da Fundação SEADE, v.9; n.1, p.41-46, jan-mar. 1995.

SILVA, M. C. P. Souza e, KOCH, I. G. Estratégias de desaceleração do texto falado. In: KATO, M. (Org.). Gramática do português falado. v. V Campinas: Ed. Unicamp/FAPESP, 1996. p.327-338. 


\section{ANEXO 1}

\section{Argentina tem apelo diferente}

SÃO PAULO - Em março de 91, quando desembarcou na Argentina, a Arisco encontrou uma situação complicada. Uma, não, duas. Primeiro problema: os produtos brasileiros, de uma forma geral, eram vistos como algo de qualidade duvidosa. Segundo: na Argentina, o consumidor não tinha a menor idéia do que era um tempero pronto - produto que tomou a Arisco conhecida no Brasil. $O$ jeito, como não poderia ser diferente, foi apelar para uma agressiva campanha publicitária.

Xuxa, falando em espanhol, e um comediante local foram os dois principais protagonistas dessa história. Um dado interessante é comparar os anúncios distribuídos pela Arisco para o Brasil e para a Argentina. "A diferença básica é que, na Argentina, você precisa reforçar os atributos do produto. No Brasil, ao contrário, o conteúdo emocional é mais importante", afirma Virgílio Souza Andrade, diretor de Marketing da empresa. Assim, o Tarantela - um molho à base de tomate - é conhecido pelos argentinos por sua "textura espessa". No Brasil, faz sucesso porque "da mais sabor a carnes e peixes".

Numa pesquisa recente, a Arisco viu que a publicidade deu resultados de sobra. De acordo com essa pesquisa, hoje os argentinos vêem a Arisco como uma empresa que sempre esteve no mercado.

JORNAL DO BRASIL, 1995:15. 


\section{ANEXO 2}

\begin{tabular}{|c|c|c|}
\hline 1 & $\mathbf{P}$ & antes de você começar o comentário $(+)$ gostaria que você dissesse a sua nacionalidade \\
\hline 2 & E & tudo bem \\
\hline 3 & $\vec{P}$ & a sua ocupação $(+)$ quer dizer $(+)$ a área de atuação $(+)$ \\
\hline 4 & & a sua idade $(+)$ a sua classe social e as relações que vocề mantém com a Argentina \\
\hline 5 & E & tudo bem $(+)$ começo logo" $(+)$ meu nome é (( foi omitido o nome do empresário)) ((risos)) \\
\hline 6 & & (+) eu eu sou brasileiro (+) é:: (+) a minha idade é 43 anos (+) eu sou gerente de uma \\
\hline 7 & & empresa de transporte internacional $(+)$ que atua no cone sul $(+)$ a minha CLASSE social" \\
\hline 8 & & $(+)$ é classe média $(+)$ é:: $(++)$ e as relações que eu mantenho com o Brasil / com o \\
\hline 9 & & Argentina $(+)$ entre o Brasil e a Argentina é relacionada com o transporte rodoviário $(+)$ \\
\hline 10 & & internacional $(+)$ então com relação a $(+)$ a essa $(+)$ a essa a essa reportagem aqui $(+)$ é:: $(+)$ \\
\hline 11 & & falando sobre a Arisco $(+)$ o que eu posso comentar não é bem a ÁREA que eu atuo $(+)$ a \\
\hline 12 & & inha área é mais o transporte uma prestação de serviço $(+)$ mais É é verdade $(+)$ os \\
\hline 13 & & odutos brasileiros até então não eram muito aceitos pela Argentina $(+)$ e menos os \\
\hline 14 & & nestíveis $(+)$ porque o argentino / eu que morei lá um tempo / até por questðes de trabalho \\
\hline 15 & & né" $(+)$ os produtos são de primeira qualidade $(+)$ então $(+)$ a $(+)$ a entrada de um \\
\hline 16 & & a digamos $(+)$ de comestível acredito que possa \\
\hline 17 & & ter acontecido é( $(+)$ é $(+)$ é essa dúvida $(+)$ quanto à qualidade $(+)$ e:: $(++)$ depois houve aí \\
\hline 18 & & $(+)$ o assunto da da da $(+)$ de do:: marketing $(+)$ de como entrar e:: pronto conseguiram \\
\hline 19 & & colocar $(+)$ até então $(+)$ eu:: achava $(+)$ que realmente os produtos brasileiros $(+)$ teriam \\
\hline 20 & & PROblema (+) para poder entrarem lá \\
\hline 21 & $\bar{P}$ & Só os \\
\hline 22 & & \\
\hline 23 & & \\
\hline 24 & & \\
\hline 25 & & a sua \\
\hline 26 & & c \\
\hline 27 & & a carne $(+)$ as massas $(+)$ \\
\hline 28 & & $2 A$ SII FIRO (t) hein" / \\
\hline 29 & & $(+) c 0 m 0$ ś \\
\hline 30 & & mas a comida em SI do DIA A DIA (+) os \\
\hline 31 & & qualquer outro produto $(+)$ que venha a \\
\hline 32 & & de da dele / a MANTEIGA $(+)$ o LEITE $(+)$ \\
\hline 33 & & e \\
\hline 34 & & da melhor qu \\
\hline 35 & & você atribui isso / é é $(+)$ uma ligação MUITO direta $(+)$ com a comida' \\
\hline 36 & & com a comida \\
\hline 37 & $\mathbf{P}$ & fora i \\
\hline 38 & & [fora isso os ou outros produtos] (+) não vejo NUNCA tivemos NEnhuma / pelo menos nós \\
\hline 39 & & prestadores de serviço / inclusive eu tô:: há vinte anos trabalhando nessa área \\
\hline 40 & & houve assim $(+)$ um ou outro desentendimento $(+)$ ma::s coisas normais $(+)$ que acontecem \\
\hline 41 & & no no comércio né $(+)$ mas $(+)$ a qualidade dos produtos brasileiros / TIRANDO os \\
\hline 42 & & \\
\hline 43 & & \\
\hline
\end{tabular}




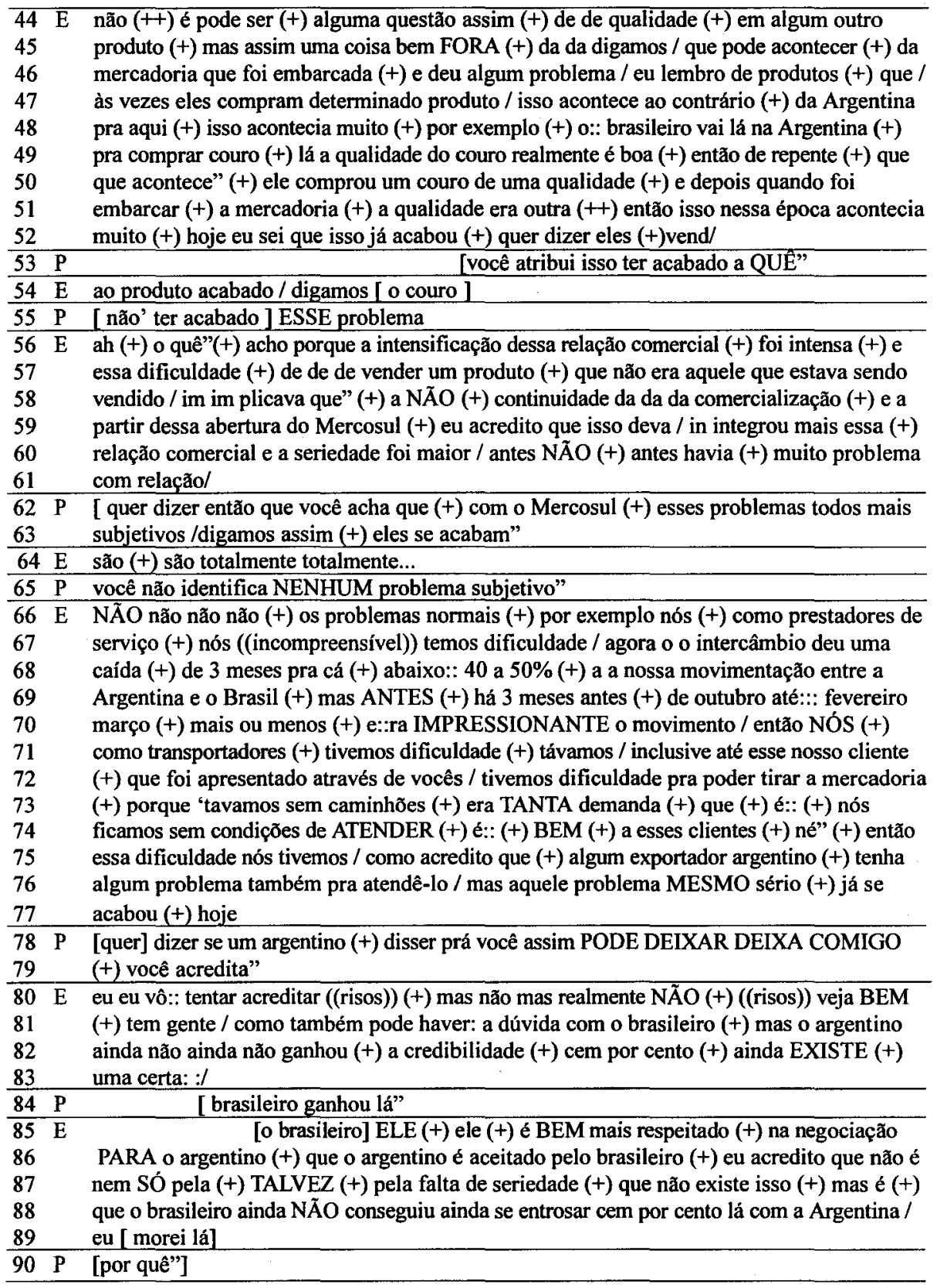




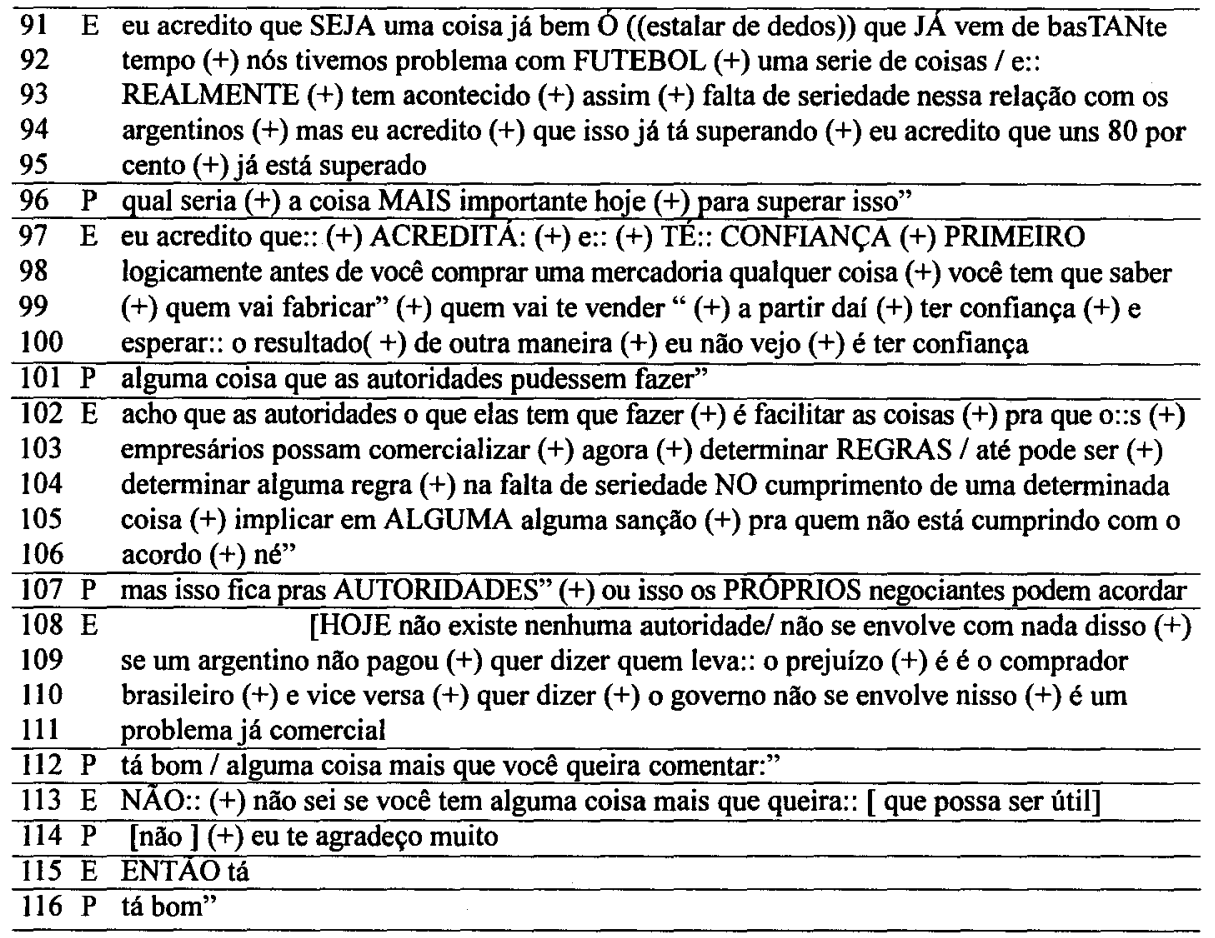




\section{ANEXO 3}

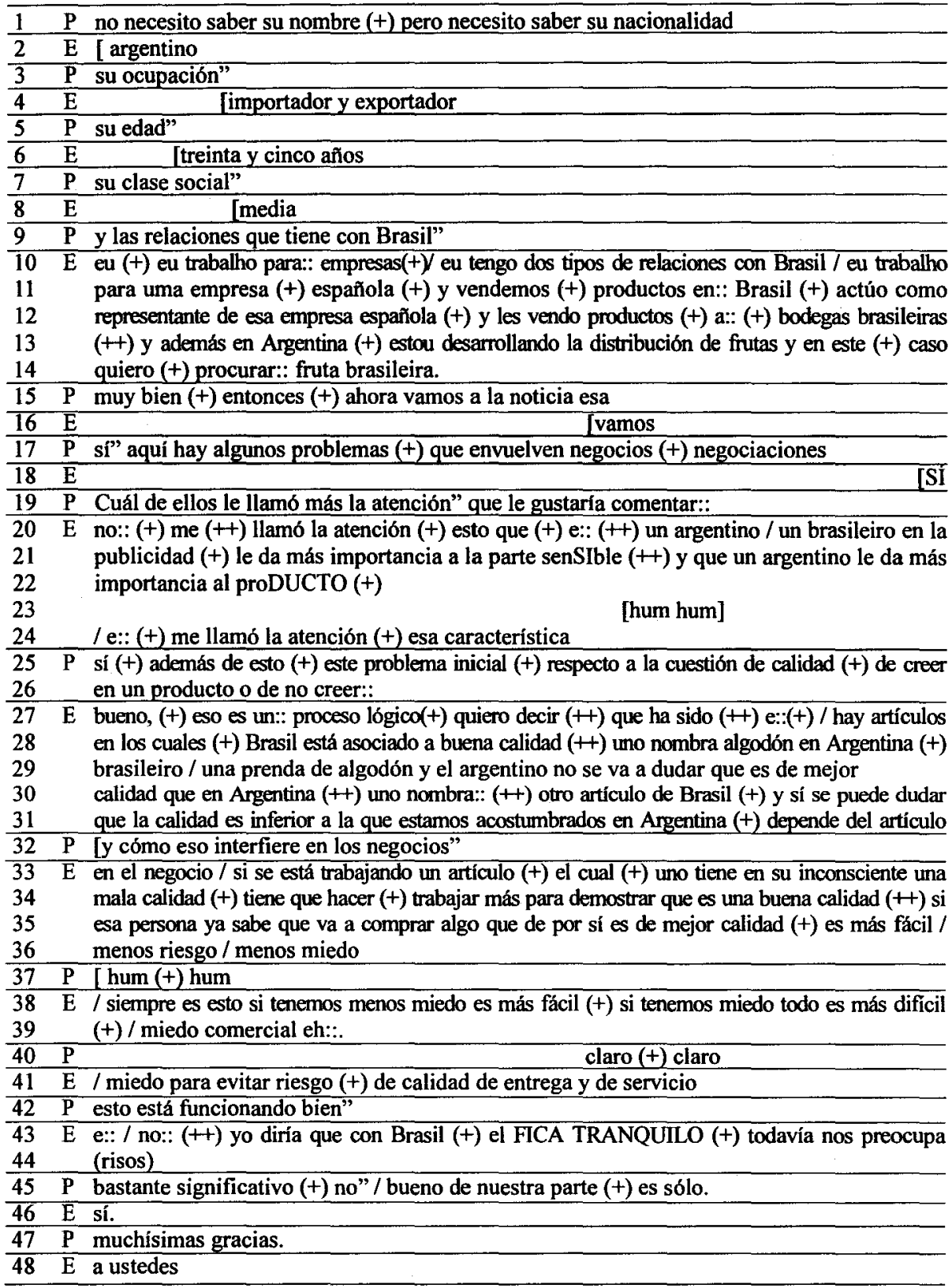

